\title{
Patient Satisfaction Survey among Inpatients in a Multispeciality Teaching Hospital, South India: A Feedback Analysis
}

\author{
${ }^{1}$ Sathish Raju N, ${ }^{2}$ Jayati Bahuguna, 3Jagiri N Rao
}

\begin{abstract}
Introduction: Patient satisfaction is a subjective phenomenon and many factors contribute directly or indirectly. In today's competitive healthcare market, patients expect more than just satisfaction. So, patient satisfaction has become a high priority to hospitals and health plans across the country and is the strongest determinant of the hospital. A patient's satisfaction may not be totally influenced by the quality of physician available, but it reflects how medical care has been delivered. Although, their main expectation is getting cured and going back to their work, but there are other factors, which affect their satisfaction. It is an important and commonly used indicator for measuring the quality of healthcare.
\end{abstract}

Aim and objectives: (a) To study the level of satisfaction of inpatients in general wards at a multispecialty teaching hospital, (b) To study the different factors affecting patient satisfaction, (c) To find the causes for dissatisfaction, if any and suggest remedial measures for improvement of services leading to better patient satisfaction.

Methodology: It is a hospital-based cross-sectional descriptive study. The research was carried out among the patients who were previously admitted in general wards of multispecialty teaching Hospital, Mysuru. Data were collected from already available inpatient feedback forms. Data thus obtained was entered in MS Excel 2013 spreadsheet and analyzed using Statistical Package for the Social Sciences (SPSS) software package version 22. About 4800 inpatient feedback forms were analyzed for the study.

Observations and results: A total of $82 \%$ of patients were satisfied with the services at the admission counter, and $84 \%$ of patients were satisfied with the discharge process; $95 \%$ of patients were satisfied with the doctor's care and attentiveness and only $1 \%$ said it to be poor; $92 \%$ of patients were satisfied with the nursing services; $79 \%$ of patients were satisfied with the quality of food served in the hospital; $79 \%$ of patients were satisfied with the cleanliness maintained; $92 \%$ of the patients are satisfied with the overall services offered.

Conclusion: It was found in the present study that most of the patients are satisfied with most of the services provided in this multispecialty teaching hospital and the doctor's care and nursing service has the highest satisfaction level, which is very satisfactory and encouraging. Major satisfiers were quality and behavior of doctors, explanation about disease and treatment

\footnotetext{
1,2Postgraduate Resident, ${ }^{3}$ Professor and Head

${ }^{1-3}$ Department of Hospital Administration, JSS Medical College and Hospital, Mysuru, Karnataka, India
}

Corresponding Author: Sathish Raju N, Postgraduate Resident, Department of Hospital Administration, JSS Medical College and Hospital, Mysuru, Karnataka, India, e-mail: sathishrajun@gmail.com by the doctors, courtesy of staff at the admission counter, behavior of nurses, timely discharge process. Dissatisfiers were lifted operators guidance, the behavior of the security guards, quality of food and dietary services. Explanation about hospital charges and costs in the billing counter, cleanliness maintained. To conclude, the majority of our patients are satisfied after availing health services. A small fraction of patients seems dissatisfied with our healthcare delivery. We have identified a few deficient areas in terms of service delivery and the same will be bridged as early as possible in order to achieve universal patient satisfaction at our hospital.

Keywords: Patient satisfaction, Teaching hospital, Wards.

How to cite this article: Raju NS, Bahuguna J, Rao JN. Patient Satisfaction Survey among Inpatients in a Multispeciality Teaching Hospital, South India: A Feedback Analysis. Int J Res Foundation Hosp Healthc Adm 2018;6(2):43-50.

\section{Source of support: Nil}

\section{Conflict of interest: None}

Ethical approval: The study was approved by the institutional Ethics committee.

\section{INTRODUCTION}

Patient's satisfaction is a person's feeling of pleasure or disappointment resulting from a service's perceived performance or outcome in relation to his or her expectations. As this definition makes it clear, satisfaction is a function of perceived performance and expectations. ${ }^{1}$ If the performance falls short of expectations, the patient is dissatisfied. If the performance matches the expectations, the patient is satisfied. If the performance exceeds expectations, the patient is highly satisfied or delighted. ${ }^{2}$ It is an important and commonly used indicator to measure the quality of care that can contribute to a balanced evaluation of the structure, process, and outcome of services. Patient satisfaction is a subjective phenomenon. It is also a multidimensional aspect as, many factors contribute directly or indirectly to patient satisfaction, including accessibility and convenience of services, institutional structure, interpersonal relationships, the competence of health professionals and a patient's expectations and preferences. More importance is now given to satisfaction of patients and their caregivers with hospital care. Patient Satisfaction is recognized as an important parameter for assessing the quality of patient care services. ${ }^{3}$ It is expected that this simple and cost-effective strategy involving continuous monitoring of expectations of patients will help 
to catalyze improvements in the quality of hospital care. It is important in case of inpatients who are seriously ill and require the plethora of nursing care and other variety of services, as the landscape of their problems make them expect highly from the hospitals. Patient satisfaction surveys will not only help the hospital administrators to revise their patient-care strategies but will also inform about patients health-related behavior. ${ }^{4}$ Patient satisfaction is one of the buzzwords of the last decade. In the last 10 years, hospitals have realized that one of the most valuable assets to their business is the loyal patient. In today's competitive healthcare market, patients expect more than just satisfaction. Patients are increasingly more demanding and more difficult to attract. So, patient satisfaction has become a high priority to hospitals and health plans across the country, because of its impact on patient loyalty, the hospital's reputation, perceptions of quality of care, employee satisfaction and retention and the health of a hospital's bottom line. Patient satisfaction is a pre-requisite for achieving the goals of healthcare as it influences the patient's decision to follow prescribed treatments and seek professional healthcare in the future. ${ }^{5} \mathrm{~A}$ patient's satisfaction may not be totally influenced by the quality of care and the quality of physician available, but it reflects how medical care has been delivered. Although, their main expectation is getting cured and going back to their work, but there are other factors, which affect their satisfaction. To provide the highest level of satisfaction that is profitable to both the patient and the provider, management must control both the perception of expectation and the quality of delivery of the healthcare services. Patients are the foundation of our medical practice, and it is very obvious that they must be satisfied while in or out of the hospital. So Patient satisfaction has become one of the strongest determinants of hospital functioning and also it is an internationally accepted factor which needs to be studied repeatedly for the smooth functioning of the hospital's/healthcare systems. ${ }^{6}$ In countries like India where healthcare is in a competitive marketplace, success will only be guaranteed if healthcare organizations have the temperature and pulse and thermometer of their ultimate customer which is the patient and the patient satisfaction is the tool much like the thermometer and stethoscope. ${ }^{7}$ Patient satisfaction is one of the important goals of any health system, but it is difficult to measure the satisfaction and gauze responsiveness of health systems as not only the clinical but also the nonclinical outcomes of care do influence the customer satisfaction. ${ }^{8}$ There are many studies available on the satisfaction of patients with regards to outpatient services but very few studies were carried out in India for measuring inpatient satisfaction with hospital services. The purpose of the present study is to carry out an evaluation of inpatient care of hospital services from feedbacks provided by indoor patients.

\section{AIM AND OBJECTIVES}

\section{Aim}

To study the level of satisfaction of inpatients in general wards at a multispecialty teaching hospital.

\section{Objectives}

- To study the level of satisfaction of inpatients in general wards at a multispecialty teaching hospital.

- To study the different factors affecting inpatient satisfaction.

- To find the causes for dissatisfaction, if any and suggest remedial measures for improvement of services leading to better patient satisfaction.

\section{RESEARCH METHODOLOGY}

- Study of currently available national and international literature on the subject.

- Study design: Hospital-based cross-sectional descriptive study

- Study area: The study was carried out in general wards of a large Multispeciality teaching hospital, Mysuru, Karnataka, India.

- Study tool: The hospital's inpatient feedback form is the main tool used for this study. About 4800 Inpatient feedback forms were analyzed for the study. Data were collected from already available inpatient feedback forms which were filled by patients who utilized the healthcare services in August, September and October 2016 and was analyzed using appropriate statistical methods. The data from the feedback forms were entered into Microsoft Excel 2013. Sorting and coding processes were performed. The descriptive statistics, including frequency and percentages were used to the inpatient satisfaction with various services. The inpatient feedback form consisted of items like excellent, good, average and poor. Patients/respondents indicated their level of satisfaction by selecting responses ranging from excellent to poor. Those selected excellent, and good were considered satisfied and who chose average and poor were considered dissatisfied. Patients were also asked if they had specific comments or suggestions regarding their encounter in the hospital. The hospital's inpatient feedback form had the following six components in it:

- Experiences with the front office

- Experience with the doctor's care

- Experience with nursing services

- Opinion about the dietary services 
- Opinion about the housekeeping services and cleanliness of the hospital environment.

- Opinion about other services provided in the hospital (lift operators, security guards behavior and guidance, overall hospital rating, etc.).

- Study Period: 3 months (August, September and October 2016)

- Unit under Study: The present study was based on the patient's feedback regarding healthcare services provided by the multispeciality teaching hospital, Mysuru.

\section{OBSERVATIONS}

\section{Front Office}

The proportion of patients/attendants indicating that time taken for admission was excellent and good were $34.3 \%$ and $59.6 \%$, respectively, average and poor were $5 \%$ and $1 \%-$ a total of $94 \%$ of satisfied patients and $6 \%$ dissatisfied patients/attendees. Regarding briefing about hospital policies, $28 \%$ patients felt it was excellent, $62 \%$ patients felt good, indicating that $90 \%$ of the patients were satisfied $8 \%$ felt it was average and $2 \%$ of them said it to be poor. With regards to friendliness and courtesy of the staff at the front office, the majority of patients $94 \%$ (this includes $35.6 \%$ and $58.3 \%$ of the patients who selected excellent and good) were satisfied, while $6 \%$ (including $4.6 \%$ and $1.3 \%$ of the patients selecting average and poor) were dissatisfied.

With regards to information about payment of services, the majority of patients $82.6 \%$ (this include $24.6 \%$ and $58 \%$ of the patients who selected excellent and good) were satisfied, while $17.2 \%$ (including $12.6 \%$ and $4.6 \%$ of the patients selecting average and poor) were dissatisfied. Regarding discharge process, 31\% patients felt it was excellent, $53 \%$ felt good, $8 \%$ felt it was average and about $8 \%$ of them said it to be poor (Graph 1 and Table 1 ).
Overall, $84 \%$ of patients were satisfied with the discharge process while $16 \%$ were not. So a good percentage of Patients were found to be satisfied with both the physical and behavioral dimensions of service and the overall patient satisfaction is good.

\section{Doctors Care}

Regarding doctors care and attentiveness during his/her interaction with them), nearly $42 \%$ patients/attendants felt it was excellent, $53.3 \%$ felt it was good-indicating that $95.3 \%$ of satisfied patients, while $4 \%$ said it was average and only $1 \%$ said it to be poor indicating $5 \%$ dissatisfied patients (Graph 2 and Table 1). Regarding explanation by a doctor about illness, treatment and medicines nearly $45 \%$ patients/attendants felt it was excellent, $45 \%$ felt it was good indicating $90 \%$ of satisfied patients, while $9 \%$ said it was average and only $1 \%$ said it to be poor thus $10 \%$ of the patients were dissatisfied.

\section{Dietary Services}

About $26 \%$ of patients felt it was excellent, $52 \%$ felt good, $17 \%$ felt it was average. Four percent of them said it to be poor (Graph 3 and Table 1). It was he one of the major dissatisfiers. Overall, $78 \%$ of patients were satisfied with the quality of food served in the hospital while $21 \%$ were dissatisfied.

\section{Nursing Services}

Regarding attitude and behavior of the nurses, promptness in meeting their needs and explanation about the process of treatment and progress and regarding medication administration to patients in time, $43 \%$ patients felt it was excellent, $49 \%$ felt good, $6 \%$ felt it was average; $1 \%$ said it to be poor (Graph 4 and Table 1). So on the whole, $93 \%$ of patients were satisfied with the nursing services while $7 \%$ showed dissatisfaction.

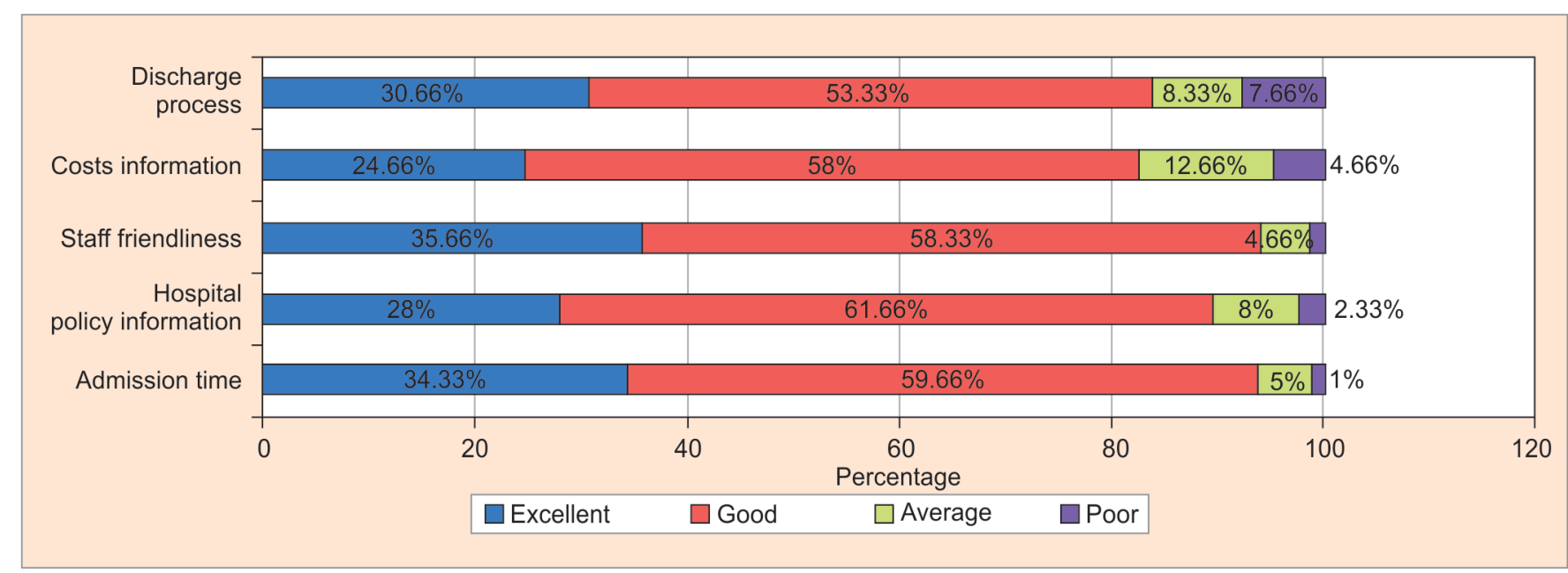

Graph 1: Distribution of patients satisfaction about front office services 
Table 1: Responses to the inpatient feedback form

\begin{tabular}{|c|c|c|c|c|c|c|}
\hline SI. No. & Division & & Excellent & Good & Average & Poor \\
\hline \multirow[t]{5}{*}{1.} & \multirow[t]{5}{*}{ Front office } & Time taken for admission & $34.33 \%$ & $59.66 \%$ & $5 \%$ & $1 \%$ \\
\hline & & Information about hospital policy & $28 \%$ & $61.66 \%$ & $8 \%$ & $2.33 \%$ \\
\hline & & Friendliness and courtesy of the staff & $35.66 \%$ & $58.33 \%$ & $4.66 \%$ & $1.33 \%$ \\
\hline & & $\begin{array}{l}\text { Information about hospital charges and costs in } \\
\text { the billing counter }\end{array}$ & $24.66 \%$ & $58 \%$ & $12.66 \%$ & $4.66 \%$ \\
\hline & & Timely discharge process & $30.66 \%$ & $53.33 \%$ & $8.33 \%$ & $7.66 \%$ \\
\hline \multirow[t]{2}{*}{2.} & \multirow[t]{2}{*}{$\begin{array}{l}\text { Doctor } \\
\text { care }\end{array}$} & $\begin{array}{l}\text { Doctors care and attentiveness during his } \\
\text { interaction }\end{array}$ & $42 \%$ & $53.33 \%$ & $3.66 \%$ & $1 \%$ \\
\hline & & $\begin{array}{l}\text { Explanation by a doctor about illness, } \\
\text { treatment, and medicines }\end{array}$ & $45.33 \%$ & $45 \%$ & $8.33 \%$ & $1.33 \%$ \\
\hline \multirow[t]{5}{*}{3.} & \multirow[t]{4}{*}{$\begin{array}{l}\text { Dietary } \\
\text { services }\end{array}$} & $\begin{array}{l}\text { Quality and taste of food as per your } \\
\text { expectation }\end{array}$ & $26 \%$ & $52.33 \%$ & $17.33 \%$ & $4.33 \%$ \\
\hline & & Food served and cleared on time & $28 \%$ & $53.66 \%$ & $15 \%$ & $3.33 \%$ \\
\hline & & $\begin{array}{l}\text { Adequate information given about the } \\
\text { procedure before starting the process }\end{array}$ & $38.33 \%$ & $52.33 \%$ & $8 \%$ & $1.33 \%$ \\
\hline & & Courteous and helpful by nurses/technicians & $41.33 \%$ & $55.33 \%$ & $3.33 \%$ & 0 \\
\hline & \multirow{4}{*}{ Nursing staff } & Attitude and behaviour & $43.33 \%$ & $48.66 \%$ & $6.66 \%$ & $1.33 \%$ \\
\hline \multirow{3}{*}{4.} & & Promptness in meeting needs & $43.33 \%$ & $49 \%$ & $6.66 \%$ & $1 \%$ \\
\hline & & $\begin{array}{l}\text { Explanation about the process of treatment and } \\
\text { progress }\end{array}$ & $43 \%$ & $49.6 \%$ & $6.3 \%$ & $1 \%$ \\
\hline & & Medications / treatment in time & $43.33 \%$ & $49 \%$ & $6.33 \%$ & $1.33 \%$ \\
\hline \multirow[t]{3}{*}{5.} & \multirow[t]{3}{*}{ Housekeeping } & Cleanliness of the facility up to your expectation & $33 \%$ & $46.66 \%$ & $19 \%$ & $1.33 \%$ \\
\hline & & Lift operators helpful and guidance & $8 \%$ & $37.33 \%$ & $52.33 \%$ & $2.33 \%$ \\
\hline & & Guidance of the security guards & $8 \%$ & $54 \%$ & $35.66 \%$ & $2.33 \%$ \\
\hline 6. & Others & Overall services offered at this Hospital & $38.66 \%$ & $53.66 \%$ & $6.33 \%$ & $1.33 \%$ \\
\hline
\end{tabular}

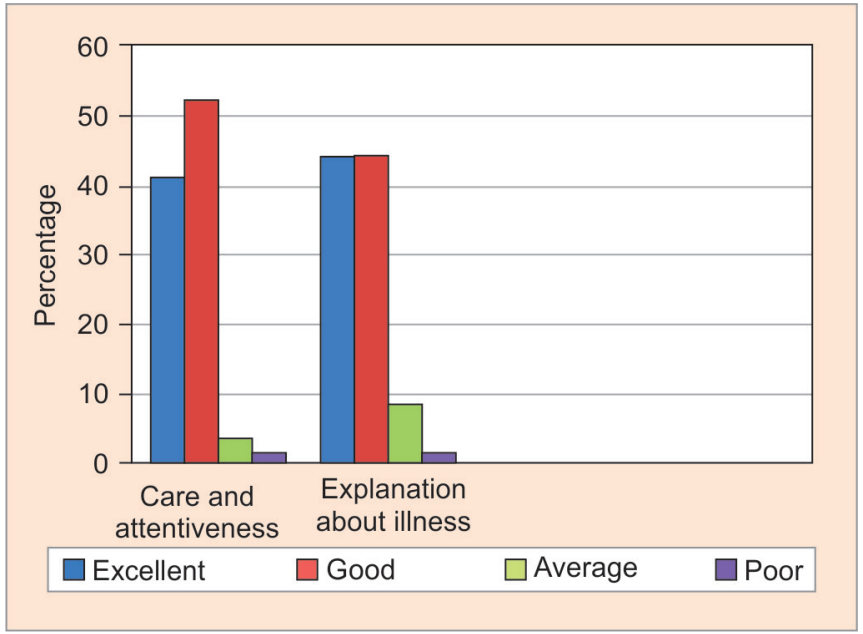

Graph 2: Distribution of patients satisfaction about doctors care

\section{Housekeeping}

Concerning satisfaction of respondents with the housekeeping services and cleanliness of the hospital environment, $33 \%, 46 \%$ chose excellent and good respectively while $19 \%$ and $1 \%$ said they were average and poor in that order (Graph 5 and Table 1). This indicates, $79 \%$ of patients were satisfied with the cleanliness maintained while $20 \%$ were not.

\section{Others}

Fifty-four percent of the patients were disturbed due to improper guidance of lift operators, while $45 \%$ patients

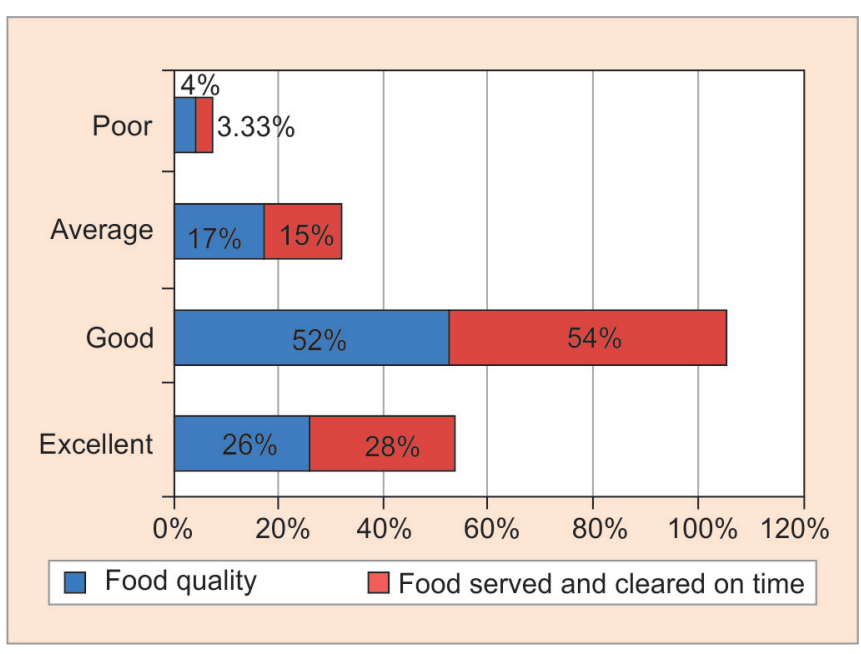

Graph 3: Distribution of patients satisfaction about dietary services

expressed their satisfaction and about $62 \%$ of the patientswere satisfied with the guidance provided by security guards while $37 \%$ of patients were not (Graph 6 and Table 1 ).

\section{DISCUSSION}

The healthcare system is basically service based, so patient experiences and their satisfaction is of the utmost importance. It has a direct impact on improving the quality of care in the health service. ${ }^{9}$ The theme of the current study touches a very important aspect of healthcare services, i.e., delivery of quality health services. We 


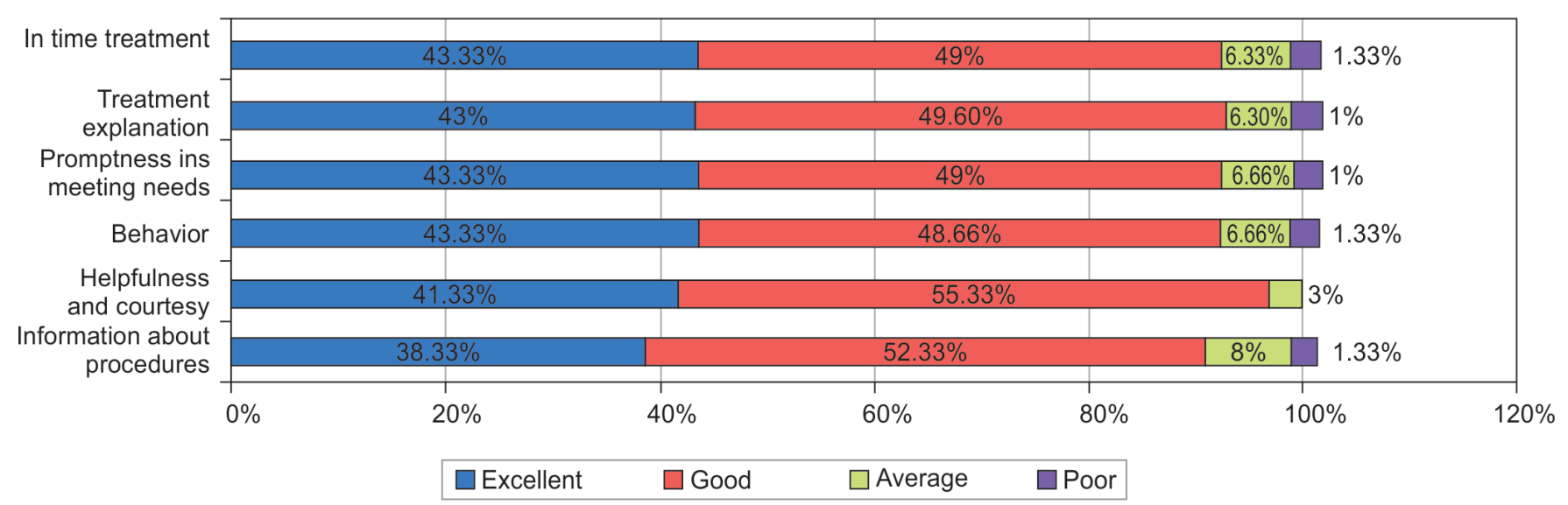

Graph 4: Distribution of patients satisfaction about nursing services

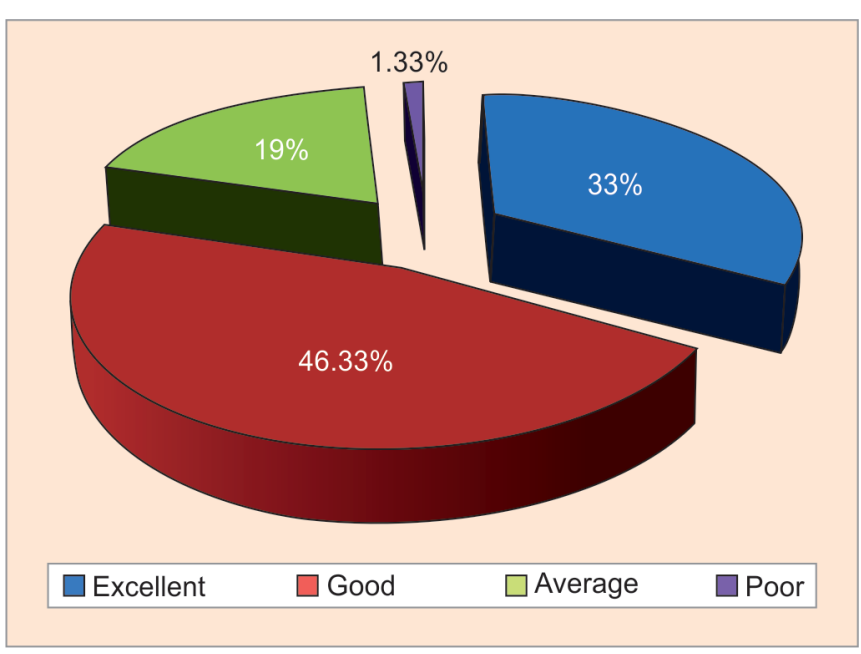

Graph 5: Distribution of patients satisfaction about housing keeping services

attempted to assess the quality of services rendered at this multispeciality teaching hospital with a view to improving them by identifying the gaps and bridging them. In addition, this study also tried to identify factors associated with the perception of quality of services and overall satisfaction of the patients. The findings of the survey are quite helpful if they are transformed into actions for improving the quality of healthcare.

Measuring patient satisfaction has many purposes, but there are three prominent reasons to do so.

It will help to evaluate healthcare services from the patient's point of view, facilitate the identification of problem areas and help generate ideas towards resolving these problems. Despite a pretty good level of patient satisfaction, a small proportion of patients expressed dissatisfaction. The fact that patients expressed dissatisfaction with the services indicates that hospital administration needs to do more in the drive towards improving services. ${ }^{10}$

In this study, most of the patients were satisfied with most of the services offered at this tertiary care

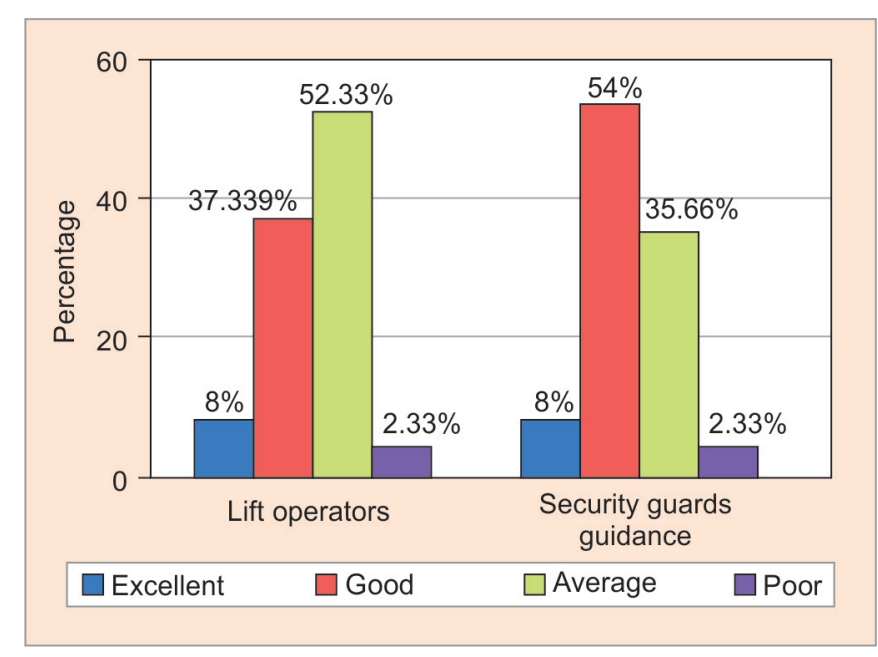

Graph 6: Distribution of patients satisfaction about other services

multispeciality teaching hospital. The overall satisfaction of patients with services received from this healthcare center came out to be $92.32 \%$ (Graph 7). This is consistent with many other studies done elsewhere.

The patients intending to utilize the hospital services will have his or her first interface with the front office of the hospital. So it is vital for patients to receive adequate information at the front office regarding hospital policies and rules. In the present study, most of the patients were satisfied with front office activities like admission procedure, information about hospital policies and procedures and discharge processes, etc. The dissatisfaction with front office activities by few respondents could be due to their visit to the hospital during holidays or when the hospital had a heavy influx of the patients because of which there may be a slight delay in the activities.

Doctor's behavior has the greatest effect on patient satisfaction. ${ }^{11}$ Attributes that hold steady for good doctor-patient relationship are sympathy and kindness, good communication between patients and 


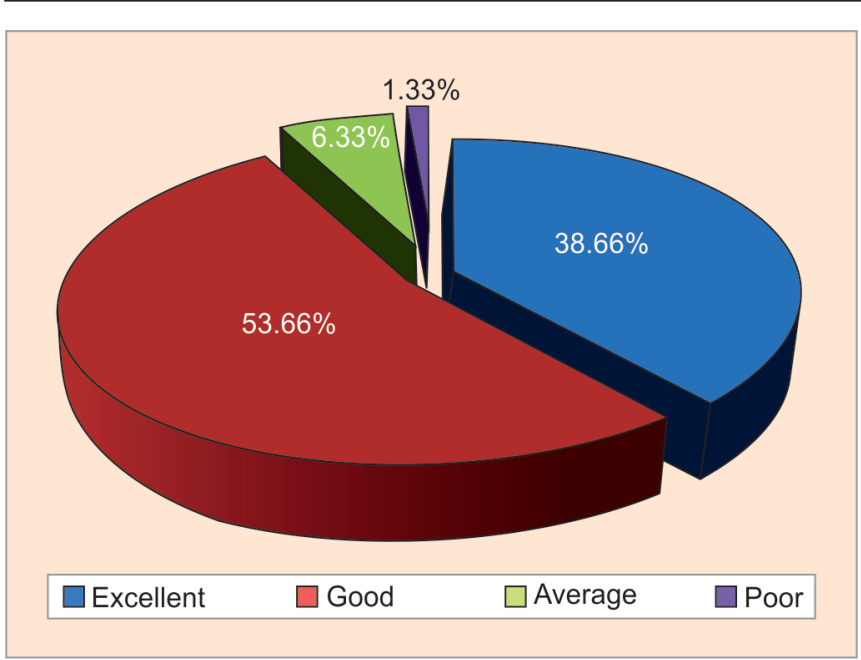

Graph 7:-Distribution of patients satisfaction about overall services offered

doctors, and patience and shared responsibility in managing illness of the patient. In the present study more than $90 \%$ of the patients were satisfied by the professional services rendered by the doctor like care and attentiveness towards them and discussion about their clinical conditions and treatment rendered, etc. which is quite similar to a study conducted by Verma et al. ${ }^{12}$ where $84 \%$ of the patients expressed their satisfaction in response to the description of disease status by doctors. In a study by Kulkarni et al. patients were more satisfied with the behavior of doctors $(87.8 \%){ }^{13}$ Bhattacharya et al. also reported $98.2 \%$ of patients were satisfied with the behavior of doctors. ${ }^{14}$

The nursing care provided by the nursing staff is regarded as the most important factor in the patient assessment of their satisfaction with healthcare. Nurses are the front-liners in healthcare; they stay with patients more than the other members of the healthcare team, and as claimed by Needleman and Hassmiller, nurses have a critical role in the delivery of high-quality, efficient care that will overall affect the patient satisfaction. ${ }^{15}$ In the present study, most of the patients were found satisfied with attention and care provided by nursing staff. In the current study, $92 \%$ of patients were satisfied with providing prescribed medications in a timely manner whereas it was $93 \%$ as studied by Verma et al., i.e., the results are quite similar.

In the present study, more than half of the patients were satisfied with the quality of food served in the hospital, while $21 \%$ of the patients expressed dissatisfaction. Aarti et al. in her study concluded that $19.8 \%$ of patients were dissatisfied with the quality of food served. ${ }^{16}$

In the present study, more than $80 \%$ of the patients/ patient's relatives said that they were satisfied with cleanliness maintained in the wards as well as of this healthcare center. The better cleanliness could be due to a sufficiently trained class of hospital housekeeping employees. Few studies have findings similar to the present study while the dissatisfaction level was at the higher side when compared to this present study. Verma et al. ${ }^{12}$ in his study reported that $73 \%$ of patients were satisfied with cleanliness maintained in wards which is lower than the present study.

Present study revealed that, more than half of the patient's/patient's relatives were not satisfied with lift operator's guidance i.e., $54 \%$ of them expressed their dissatisfaction, the probable reason could be due to shortage of staffs which may cause overburden of work on them, and the staffs may be illiterates, so more regular training sessions on behavioral communication is required.

This study has several strengths. First, we have conducted this study to improve the quality of services rendered at this multispecialty teaching hospital. To our knowledge, such domain has not been analyzed by experts of the field in this hospital. Second, the paucity of literature also warranted this study. Third, data collection was done by a single author to reduce interobserver variation.

On the other hand, there have been a few limitations as well. First, the current study catered only indoor patients. To evaluate the actual quality of services it should have included OPD and emergency services also. Second, specialty ward wise services could not be compared due to time constraints. Third, the findings emerging out of the current study cannot be generalized or extrapolated to all other hospitals of India as the satisfaction levels of patients will be different in different studies. The responses of patients depend upon their socio-economic profile, personality, and their perceptions; some may be satisfied with average services, while others may be dissatisfied even with the best. In the present study, most of the respondents belonged to rural areas and middle or low socioeconomic class. Henceforth, it implies caution while comparing results from such a survey wherein the outcome may be largely associated with the socio-demographic profile of the study population.

\section{CONCLUSION}

Feedback of patients is one of the key parameters in assessing the quality of hospitals. The feedback results showed that most of the patients were satisfied with most of the services in Hospital under study and the doctor's care and nursing services have the highest satisfaction level, which is very satisfactory and encouraging but there is always a scope for improvement. More than $85 \%$ of the patients rated most of the parameters as good or excellent. 


\begin{tabular}{l} 
Major satisfiers were: \\
- $\quad$ Quality and behavior of doctors \\
- $\quad$ Courtesy of staff at the admission counter \\
- $\quad$ Behavior of nurses. \\
\hline
\end{tabular}

\section{RECOMMENDATIONS}

An assessment of the level of patient satisfaction related to inpatient care reminded us of certain areas that need improvements, to upgrade the hospital's service quality further. Hence the following recommendations are made:

\section{Front Office}

It was observed that briefing about the hospital charges and costs at the billing counter has got an average response of $13 \%$ and poor response of $5 \%$. Hospital charges should be explained well to the patient/patient relatives before getting admitted to the hospital. However, this policy of revising rates may be looked into. There should be package charges for some procedures to avoid running around by the patient's attendant for minor requirements.

\section{Behavior of Doctors}

Although 91\% of responses showed that the doctors at Hospital were excellent, yet around $9 \%$ of people felt that the doctors have become less sensitive and empathetic to their problems. The new generations of doctors should be trained and the value of empathic care and soft skill must be re-emphasized

Dietary services have got a $17 \%$ average and $14 \%$ poor response. It was the second major dissatisfier. The quality and quantity of food, especially the quality of idly and its presentation should be improved. There were also some complaints of normal diet being given to diabetic patients and this needs careful monitoring.

\section{Housekeeping}

The cleanliness of toilets should be improved. Although it may be done thrice a day and housekeeping staff is posted in all the wards round the clock in sufficient numbers to maintain the cleanliness of the wards/toilets, frequent and surprise checks by housekeeping executives and administrators will instill a sense of responsibility and alertness among housekeeping staff.

The timing for activities like nursing, cleaning, ward rounds should be fixed, so that the patient is mentally prepared for the same and can take rest at other time and they should be regularly trained and sensitized about how to improve their image and behavior.
Dissatisfiers were:

- Lift operators guidance

- Behavior of the security guards

- Quality of food and dietary services.

- Explanation about hospital charges and costs in the billing counter

- Cleanliness maintained

\section{Behavior of Lift-operators/Security Guards}

Fifty-two percent of the patients were disturbed due to improper guidance of lift operators and about $35 \%$ of the patients we are not satisfied with the security guards behavior. Some people complained about the bad behavior of hospital security personnel. Security guards and lift operators must be trained properly by the hospital authorities. The behavior of hospital staff should be improved by conducting special sessions for behavior change communication.

A follow-up study is recommended to be conducted among healthcare providers on challenges they are facing in meeting patients 'expectations.

\section{ACKNOWLEDGMENTS}

Authors would like to thank the institution for permitting to conduct this study.

Authors would also like to thank public relation officer Mr. Jeevan for his constant support in the process of providing data and required information for this study.

Authors are also grateful to authors, editors, and publishers from where the literature for this article has been reviewed and discussed.

\section{REFERENCES}

1. Linder-Pelz SU. Toward a theory of patient satisfaction. Journal of Social Science and Medicine. 1982;16(5):577-582.

2. Oliver RL. A conceptual model of service quality and service satisfaction: Compatible goals, different concepts. In: Swartz TA, Bowen DE, Brown SN, and Stephen,. In: Advances in services marketing and management: Research and practice. Greenwich, CT: JAI Press; 1993. p. 65-85.

3. KishoreJ.Healthcare Delivery System In India. Kishore's National Health Programs of India National Policies and Legislations Related to Health. In: 9th ed. Century Publications; p. 72-75.

4. Pascoe GC. Patient satisfaction in primary healthcare: a literature review and analysis. Eval Program Plann. 1983 Jan 1;6(3-4):185-210.

5. Garg N, Gupta SK, Mahesh R. Patient Satisfaction Survey at a Tertiary Care Speciality Hospital. International Journal Research Foundation for Hospital and Healthcare Administration. 2014;2(2):79-83.

6. Ahmad I, Ud Din S. Patients' satisfaction from the healthcare services. Gomel Journal of Medical Sciences. 2010 Jun;8(1).

7. Gyani GJ, Thomas A. Jain M, Menon BG. Monitoring and Improving Patient Satisfaction. In: Handbook of Healthcare Quality \& Patient Safety. 2nd ed. New Delhi: Jaypee Brothers Medical Publishers LTD; p. 319-326. 
8. Agrawal D. Health sector reforms: Relevance in India. Indian Journal of Community Medicine. 2006; 31:220-222.

9. Deepa R, Pradhan P. Patient Counseling at Aravind Eye Hospital. Illumination. Illumination. 2002; 2(3):13-17.

10. Qadri SS, Pathak R, Singh M, Ahluwalia SK, Saini S, Garg PK. An Assessment of Patients Satisfaction with Services Obtained From a Tertiary Care Hospital in Rural Haryana. International Journal of Collaborative Research on Internal Medicine \& Public Health. 2012;4(8):1524-1537.

11. Rao KD, Peters DH, Bandeen-Roche K. Towards patientcentered health services in India--a scale to measure patient perceptions of quality. International Journal of Quality Healthcare. 2006 Dec;18(6):414-421.

12. Verma N, Kamble N, Bhawnani D, Makade K, Dengani M, Kaushik T. Evaluation of level of satisfaction among indoor patients attending in a tertiary care hospital of Rajnandgaon (C.G.), India. International Journal of Community Medicine and Public Health. 2018 Apr;5(4):1428-1433.

13. Kulkarni MV, Dasgupta S, Deoke AR, Nayse N. Study of satisfaction of patients admitted in a tertiary care hospital in Nagpur. National Journal of Community Medicine. 2011;2(1):37-39.

14. Bhattacharya A, Menon P, Koushal V, Rao KLN. Study of patient satisfaction in a tertiary referral hospital. Journal Academy of Hospital Administration. 2003;15:11-15.

15. Needleman J, Hassmiller S. The role of nurses in improving hospital quality and efficiency: real-world results. Health Aff (Millwood). 2009;28(4):625-633.

16. Aarti Verma,R. K. Sarma. Evaluation of the exit proformas in use at special wards of public sector tertiary care center. Journal of Academy of hospital administration. 2000;12(1). 